\title{
Editorial
}

\section{Salud bucal en América Latina}

Manuel Antonio Mattos-Vela ${ }^{1, a, c}$, Hilda Moromi Nakata ${ }^{1, b, c}$

${ }^{1}$ Universidad Nacional Mayor de San Marcos, Facultad de Odontología. Lima, Perú.

a Doctor en Estomatología.

${ }^{\mathrm{b}}$ Magíster en Administración de la Educación Universitaria.

c Editor general de la revista Odontología Sanmarquina.

d Directora de la revista Odontología Sanmarquina.

\section{Correspondencia:}

Manuel Antonio Mattos-Vela: mmattosv@unmsm.edu.pe Universidad Nacional Mayor de San Marcos, Facultad de Odontología. Calle Germán Amézaga 375. Lima 1, Perú.

ORCID: 0000-0002-5701-1961.

\section{Oral health in Latin America}

Recibido: 21/01/20

Aceptado: $25 / 01 / 20$

Publicado: 24/02/20

Las enfermedades dentales se encuentran entre las más prevalentes del mundo, además presentan una carga de tratamiento general en aumento, especialmente en países de bajos y medianos ingresos, por ello, existe una gran necesidad de proceder de manera oportuna para proporcionar evidencia procesable y políticas para mejorar la atención de la salud bucal a nivel mundial ${ }^{1}$.

Informes de la OPS indican que la prevalencia y severidad de caries dental, medido con el índice CPOD, han disminuido en las últimas décadas en los países de la región de las Américas ${ }^{2}$. Sin embargo, existe poca información sobre el estado actual de las condiciones bucales y el abordaje de esta problemática en los países de América Latina.

La revista Odontología Sanmarquina dentro de su misión de difundir conocimiento científico confiable y relevante a la comunidad odontológica internacional ha planteado publicar el 2020, en su sección "Notas científicas", una serie de artículos acerca del estado de la salud bucal en los países latinoamericanos. Para ello, se está invitando a los responsables nacionales de salud bucal o a los que tengan experiencia y trayectoria en la salud pública bucal de su país para que escriban un artículo sobre este tema. También se están realizando gestiones para entrevistar a un funcionario de la OPS para que describa la realidad de la salud bucal en la región latinoamericana y los esfuerzos que viene realizando esta institución para colaborar con la mejora de la salud.

Se ha sugerido a los autores de estas notas que desarrollen en su artículo el estado de la salud bucal, las políticas y estrategias aplicadas en el país, resultados obtenidos en los últimos años, lecciones aprendidas y retos futuros, además de algún otro punto relevante que deseen incluir. Ellos tienen la libertad de modificar esta propuesta de acuerdo a la información que puedan obtener en sus países.

La revista diseñó este proyecto de compartir experiencias en salud bucal entre los distintos países de nuestra región, esperando sea un aporte enriquecedor para toda la comunidad odontológica (dentistas generales y especialistas, estudiantes y docentes universitarios, profesionales que trabajan en salud pública y los que toman decisiones en las políticas de salud bucal).

Si bien estas notas científicas se están elaborando por invitación a un autor, igualmente su contenido pasa por un proceso de revisión por pares externos, tal como sucede también con los artículos originales, casos clínicos y artículos de revisión que se publican en la revista.

El comité editor agradece a los investigadores que aceptaron la invitación y actualmente se encuentran trabajando en este tema. Su esfuerzo no será en vano, sino 
que será un aporte actual para conocer la realidad de la salud bucal de nuestra región.

En este número de la revista se presenta una nota científica sobre la salud bucal en Venezuela, de la cual en los últimos años no se ha contado con información oficial confiable. La Dra. Yajaira Romero, jefa del Departamento de Investigación de la Facultad de Odontología de la Universidad de Los Andes narra, con mucha transparencia y en base a la evidencia que ha podido recolectar, la situación crítica en la que se encuentra la salud bucal en su país debido a la aguda crisis que padecen. Este artículo es muy pertinente en estos tiempos en donde se ha incrementado lo que se denomina la migración sur/sur (migraciones entre países de bajos y medianos ingresos), de manera especial de Venezuela a otros países latinoamericanos. Se está planteando este fenómeno migratorio como un determinante social que incide directamente sobre la salud general y bucal, y sobre la calidad de vida del migrante por la influencia de factores estructurales e intermedios que operan a lo largo del proceso migratorio ${ }^{3}$.

\section{Referencias bibliográficas}

1. Schwendicke F, Giannobile WV. Research for prevention of oral/dental diseases: how far have we come? [editorial]. J Dent Res. 2020;99(1):5-7. DOI: 10.1177/0022034519889054.

2. Pan American Health Organization. Proposed 10-year Regional Plan on Oral Health for the Americas: final report. 160th Sesion of the Executive Committee; 2017 26-30 June; Washington, DC. Washington, DC: PAHO; 2017 (Document CE 160/INF/7) [citado 20 de enero 2020]. Disponible en: http://iris.paho.org/xmlui/ bitstream/handle/123456789/34217/CE160-INF-7-e. pdf? sequence $=1 \&$ isAllowed $=y \& u a=1$

3. Murillo-Pedrozo AM, Agudelo-Suárez AA. La migración sur/sur como un determinante social de impacto en las desigualdades e inequidades en salud bucal en Latinoamérica [simposio]. Rev Peru Med Exp Salud Publica. 2019;36(4):692-9. DOI: 10.17843/rpmesp.2019364.4908. 